\title{
Subsidiariedade, direitos humanos e meio ambiente: um olhar sobre a política pública do pós-impacto ambiental
}

O presente trabalho tem como objeto de estudo analisar a subsidiariedade no sentido etimológico realizando um itinerário pela origem do termo e sua relação com as Encíclicas Papais. Num segundo instante, será feita a relação da subsidiariedade e o papel dos direitos humanos na esfera municipal. Em terceiro plano, será realizando um prognóstico dos desastres ambientes no espaço local e tomada de decisão dos agentes governamentais quanto a população diretamente afetada e a necessidade de abertura a comunidade na tomada de decisão em relação a assistência ao pós-impacto e nos planos contingenciais.

Palavras-chave: Município; Desastre Ambiental; Direitos Humanos; Políticas Públicas; Subsidiariedade.

\section{Subsidiarity, human rights and the environment: a look at the post- impact public policy}

\begin{abstract}
The present work has as object of study to analyze the subsidiarity in the etymological sense realizing an itinerary by the origin of the term and its relation with the Papal Encyclicals. In a second moment, the relation of subsidiarity and the role of human rights in the municipal sphere will be made. Thirdly, it will carry out a prognosis of environmental disasters in the local space and decision-making of government agents regarding the population directly affected and the need to open the community in decision making regarding post-impact assistance and contingency plans.
\end{abstract}

Keywords: Municipality; Environmental Disaster; Human Rights; Public Policy; Subsidiarity.

Topic: Legislação e Direito Ambiental

Reviewed anonymously in the process of blind peer.

Márcio Bonini Notari

Universidade de Santa Cruz do Sul, Brasil

http://lattes.cnpq.br/1879425259745073

marcionotari@hotmail.com

Karla Regina Cardoso

Universidade de Santa Cruz do Sul, Brasil http://lattes.cnpq.br/1372037399330372

karla.cardoso@ymail.com
Received: 20/07/2017

Approved: 21/10/2017
Referencing this:

NOTARI, M. B.; CARDOSO, K. R.. Subsidiariedade, direitos humanos e meio ambiente: um olhar sobre a política pública do pós-impacto ambiental. Revista Ibero-Americana de Ciências Ambientais, v.8, n.4, p.295-308, 2017. DOI: http://doi.org/10.6008/SPC2179$\underline{6858.2017 .004 .0024}$ 


\section{INTRODUÇÃO}

O estudo ora proposto tem como pressuposto uma análise acerca da parte histórica do tema da subsidiariedade e suas origens teóricas e pragmáticas elencadas nas Encíclicas Papais, e a forma como se originou a relação entre comunidade local, numa perspectiva papal levando em conta os valores liberais, os atores sociais com o objetivo de promover o bem-estar social e coletivo, a dignidade dos indivíduos e a participação cidadã na vida política, independente da condição social, com aceitação de todos os indivíduos, em uma relação político jurídica entre Sociedade e Estado.

Deste modo, o questionamento na pesquisa apresentada, o desenvolvimento sustentável do município depende da descentralização de poderes sendo este caminho necessário para fortalecimento dos mecanismos de gestão local, em detrimento da centralização quanto à tomada de decisões no município, eis que essa abordagem estabelece um espaço de possibilidades operativas para atingir a sustentabilidade nos planos de desenvolvimento, promovendo novas regras de convivência entre o governo local e comunidades locais, para uma gestão pública compartilhada.

Ainda, questiona-se estabelecendo a reflexão do princípio da subsidiariedade em se tratando de desastres ambientais, pós-impacto em razão da faltas de recursos em desastres inesperados, a própria gestão pública centralizadora e ausência falta de articulação entre as instituições democráticas (Executivo, Legislativo, Judiciário), o que leva a burocratização estatal, centralização administrativa e a inercia da sociedade civil afetada, inviabilizando a possibilidade de articulação entre os entes sociais e a administração pública no espaço local.

A descentralização sustentável se apresenta com uma forma de transformação do espaço local, com a participação societal para a edificação de um novo ambiente entre o governo local e a comunidade, cujo objetivo é transformar o município no veículo da construção da cidadania democrática, na busca pela aproximação entre governantes e cidadãos, semeando novos valores de responsabilidade social, promovendo a solidariedade entre os atores para a solução de problemas específicos, fundamental para a concretização dos direitos humanos, pois a cidade está em constante mutação de caráter público, econômico e social, devido a processo globalizatório.

\section{REVISÃO TEÓRICA}

\section{Subsidiariedade}

O princípio da subsidiariedade remonta de épocas onde era somente uma ideologia frente aos acontecimentos que cada filósofo e sociólogo vivenciam o caos de suas sociedades, políticas e economia. A subsidiariedade tem sua origem etimológica no latim subsidium que, segundo o dicionário Langenscheidts Schulwörterbuch lateinisch - deutsch, significa reserve ou Hilfsmannschaft, ou seja, 'reserva' ou 'equipe de ajuda'.

No entanto, há autores como Millon-Delsol, Benoist Baracho, Papa Bento XVI e Delperee conceituam a subsidiariedade conforme percepção política, social e econômica, porém concluem da mesma forma que a subsidiariedade é uma 'suplência'. entende que o termo subsidium seja uma reserva que se invoca em caso 
de necessidade, ou seja, quando inserido no meio político-social a ideia de subsidiariedade se refere ao papel da autoridade em geral e não apenas à autoridade do Estado.

Papa Bento XVI (2009) em sua Carta Encíclica define a subsidiariedade como sendo un aiuto alla persona, attraverso l'autonomia dei corpi intermedi, proporcionando uma emancipação do indivíduo com responsabilidade. Salienta, ainda, que a subsidiariedade respeita e reconhece a dignidade humana tornandose um 'antídoto contra toda forma de assistencialismo paternalista'. Benoist (2000) define a subsidiariedade como sendo um termo bastante usado em tropas ou reservas para reforçar o exército, quando este solicita. Numa acepção política, o princípio da subsidiariedade é um princípio limitador e regular, porque ele limita a ingerência do Estado numa comunidade inferior, a menos que seja solicitado.

Baracho (1996) exprime o conceito de subsidiariedade "sob a compreensão de que existe a noção de alguma coisa". Salienta que o significado do termo sofre mudança quando este passa para uma esfera jurídica ganhando roupagem de princípio. Pode ser entendido com sentido de supletividade, dando ensejo a dois significados: o de complementação e o de suplementação.

No primeiro caso, ensaia a ideia de uma suplência, ou seja, algo que venha em segundo plano. No entanto para a temática a que se destina, o termo pode designar a uma ideia de decidir, que pode ser atribuída a administração pública. Sendo assim, nestes termos, o princípio implica em 'conservar a repartição entre duas categorias de atribuições, meios, órgãos que se distinguem uns dos outros por suas relações entre si'. A complementação, por sua vez, dá validade ao princípio na medida em que esta complementa outro em ordenamentos jurídicos distintos.

Delperee (2013) define a subsidiariedade como sendo algo que não se impõe, e não se dá. Ela se constrói, como resultado de uma estratégia. Para o autor, a subsidiariedade vem em segunda ordem, no tempo ou no espaço, pois a sociedade política leva certo tempo para medir os problemas da política pública. Ela surge como um remédio para reparar as situações difíceis. É um método para atingir um objetivo - por exemplo, o bom funcionamento das instituições educacionais ou a boa partida entre requisitos acadêmicos e as expectativas da sociedade. O princípio da subsidiariedade invoca uma relação social e de poder, uma relação entre um grupo pequeno de indivíduos de ordem inferior e uma coletividade de pessoas mais elevada, desta forma, está relacionado na organização da sociedade.

Para Baracho (1996, p. 26) esta vinculação do princípio da subsidiariedade com a organização da sociedade ocasiona uma preocupação jurídica, pois, além de o invocado princípio ser uma prerrogativa do ideal canônico, ele, o é, também, na relação político-jurídico entre o Estado e a sociedade civil. No entanto a subsidiariedade, muito antes de ser rogada pelos princípios canônicos era uma esperança, uma ideologia social, política e econômica traduzida nas linhas de Aristóteles, São Thomas de Aquino e Althusius. Assim,

[...] para o Estarigita a sociedade ideal era traduzida por grupos de pessoas que desempenhavam tarefas específicas capazes de suprirem as suas próprias necessidades. Enquanto a família se preocupava em atender às necessidades da vida diária, a cidade, por sua vez, se ocupava com uma vida diária mais ampla e complexa. Contudo, na sociedade de Aristóteles, a cidade é o único órgão estritamente político com condições de atingir os princípios da autarquia, definido assim como autossuficiente, sinônimo de perfeição. A cidade aristotélica vai mais além do que uma simples meta de suplência, pois a sociedade civil não se resume numa associação unitária, nela os indivíduos se reúnem para conseguir 
o que cada um na sua individualidade não conseguiria obter, como a riqueza e a segurança. (MILLON-DELSOL, 1992)

Em relação a São Thomas de Aquino, carrega em seu discurso semelhanças da cidade idealizada por Aristóteles, até mesmo, por sofrer influência do discurso do Estarigita em sua filosofia. Contudo, MillonDelsol (1993) salienta que na doutrina de Thomas de Aquino a pessoa é um mundo em si mesmo responsável por seu destino, mas insuficiente para alcançar a felicidade esperada. O poder político existe para servir a sociedade, porém a sua finalidade é de garantir, aumentar ou manter a perfeição do ser humano por quem ele é responsável.

Para Thomaz de Aquino, a subsidiariedade leva em consideração duas comunidades importantes, a cidade e a família. O Estado tem o papel de proporcionar as comunidades sociais e familiares melhores condições de vida, ficando à família a responsabilidade de proporcionar a sua própria suficiência. O Estado somente interfere quando os dois grupos não conseguem efetuar atividades que ambas não conseguiriam com plena eficácia.

Johannes Althusius, jurista e filósofo teólogo desenvolveu suas teorias sobre a influência calvinista com uma política fundamentada num sistema de corporativismo (Körperschaften) medieval alemão, sobretudo as associações mutualistas e cooperativistas (Genossenschaften) no qual já descansava o princípio da vida em comum e o da propriedade indivisível. O pacto de sociedade não é para ele, um único fato, que intervém, de uma vez por todas, mas um dado que está presente em todos os níveis resultante da natureza social do homem. O seu sistema não é caracterizado por uma hierarquia de contratos sociais, mas sim por uma hierarquia de corpos sociais que estão ligados uns aos outros através de uma série de contratos políticos.

Além do mais, Althusius se confirma como o primeiro defensor do princípio da subsidiariedade pósmedieval ao afirmar que a ingerência do Estado só é plausível quando os grupos pequenos não conseguem desempenhar suas tarefas com eficiência. Desta forma, a subsidiariedade é um princípio sobre o qual limita o poder de ingerência do Estado, permitindo a sua contribuição, somente quando é solicitada a gestão de suplência pelas comunidades inferiores. Portanto, é um princípio que visa o equilíbrio e regulamentação, mantendo vivas as iniciativas da comunidade inferior, evitando que sejam sufocados pelas instâncias superiores.

A teoria de Althusius teve grande contribuição para a Teoria dos Contratos de Rousseau, como confere Gierke, ao citar uma passagem da Lettres écrites de la montagne, em que o nome de Althusius é explicitamente citado por Rousseau. No entanto, a diferença entre ambos está no fato de que, para Rousseau, o contrato social se dá somente indivíduos, assim como na doutrina liberal, enquanto que o pacto social, para Althusisus, repousa na união progressiva das comunidades orgânicas de dimensões variadas onde os indivíduos não fazem parte, ou seja, o contrato se dá por meio de uma comunidade já existente. Desta forma, a transformação de indivíduos em cidadãos não se dá por uma associação voluntária, mas sim por uma lenta elaboração social a partir de comunidades primarias.

A suplência defendida por Tocqueville se fundamenta na crítica a política centralizada francesa no século XIX. Sugere a ideia de limitação do poder do Estado, visando devolver a vida a uma sociedade enferma. A forma de se atingir o bem estar social e político parte do princípio da descentralização estatal e a revitalização de uma política devolvendo aos 
cidadãos a valoração do trabalho do sentimento de pertencimento da comuna. Hegel, por sua vez, encontra-se numa Alemanha esgotada por uma anarquia causada pelo inchaço do individualismo, contudo, defende a possibilidade de coordenar o individualismo e o poder do Estado. Para Proudhon a ideia de suplência se traduz num sistema federalista, o qual reconcilia, definitivamente, o cidadão e o poder. Defende a necessidade da formação de uma sociedade autônoma, com um estado intervencionista, somente quando solicitado. Thaine, por sua vez, motiva o direito de suplência numa teoria da ação, ou seja, uma ação capaz de garantir a felicidade pessoal e a eficácia social. (MILLON-DELSOL, 1993)

Após séculos de ideologia a subsidiariedade ganha seu lugar de destaque na doutrina da igreja católica, quando despertou por vez a necessidade de respaldar a segurança do cidadão contra as maléficas políticas socialista e marxista que começavam a brotar na Europa, principalmente com a Encíclica do Quadragesimo Anno, de 15.05.1931, o que em por objetivo restaurar e aperfeiçoar a ordem social em conformidade com a Lei Evangélica no XL aniversário da Encíclica de Leão XIII, escrita pelo Papa Pio XI.

Nas célebres palavras o Pontífice roga aos governantes a subsidiariedade como instrumento de governança a história o demonstra abundantemente, que, devido à mudança de condições, só as grandes sociedades podem hoje levar a efeito o que antes podiam até mesmo as pequenas; permanece, contudo imutável aquele solene princípio da filosofia social: assim como é injusto subtrair aos indivíduos o que eles podem e efetuar com a própria iniciativa e indústria, para confiá-lo à coletividade, do mesmo modo passar para uma sociedade maior e mais elevada o que sociedades menores e inferiores podiam conseguir, é uma injustiça, um grave dano e perturbação da boa ordem social. O fim natural da sociedade e da sua ação é coadjuvar os seus membros, não destruí-los nem absorvê-los.

Diante de tamanha manifestação se traz à baila as palavras de Delperee (2013) o qual afirma que o princípio da subsidiariedade "se afirma no estado e não contra o estado ou fora do estado", devendo ser compreendido como um princípio que visa resolver alguns dos problemas que surgem nas grandes instituições, ou seja, em instituições complexas. Atenta ainda, o autor, para o fato de que a subsidiariedade, conforme descrita pelas encíclicas Papais, mais precisamente pela Quadragesimo Anno encontra-se num terreno reflexivo e de ação, é mais construtivo do que destrutivo.

A subsidiariedade quando vestida de princípio se torna algo além de um pressuposto metafisico, ou seja, se torna, segundo Delpree (2013) um princípio de organização do Estado (uma regra de "divisão de poderes", onde a intervenção do Estado é de suplência, quando as comunidades inferiores não conseguirem realizar as competências a elas atribuídas), um princípio de funcionamento do Estado (onde cada órgão, cada esfera de poder tem por direito intervir nas áreas de suas competências), um princípio de hierarquia de valores no Estado (o Estado assim como os cidadãos é dotado de poderes e de deveres, e competências, mas também são os meios).

Sobre estas bases o princípio da subsidiariedade, passou a ser a base político-social da União Europeia, tendo como premissas a descentralização de poderes, ou seja, que cada Estado seja composto de vários níveis de decisão e de autonomia; que deve haver a preferência dos níveis governamentais mais próximos dos cidadãos para a tomada de decisão e de atuação, de haver respeito a atuação dos níveis mais próximo do cidadão até o seu limite de atuação, e que a ingerência do nível superior se justifica pela ineficiência do nível inferior. Neste cenário, a subsidiariedade, quer seja na sua forma de princípio ou na sua 
forma pura etimológica é um meio pelo qual o Estado tem a função de proporcionar ao cidadão e a sociedade garantias fundamentais e dignas da vida humana.

\section{O papel do município na proteção dos direitos humanos}

Com a onda da globalização o Estado vem enfraquecendo cada vez mais dificultando a atuação da União, dos municípios e dos Estados no controle de políticas públicas eficazes. Neste quadro de desenvolvimento populacional o Estado se torna grande demais para resolver os problemas pequenos enfrentados pela sociedade e pequeno demais para solucionar problemas grandes. Com o processo de redemocratização ocorrido a partir da Constituição de 1988, o Estado, por meio da descentralização de poderes, concebeu aos municípios autonomia decisória facilitando desta forma o envolvimento das comunidades na tomada de decisão.

Desta forma o município vem se mostrando cada vez mais uma instituição complexa, pois decorre de uma multiplicidade de finalidades e interesses públicos no qual o município está empenhado a proteger e promover o desenvolvimento de novos papéis e responsabilidades no campo dos direitos humanos. Tanto o é que na Europa a Carta de Autonomia Local guarda no seu artigo 4.3 a regra jurídica de distribuição de competências entre o Estado e os entes regionais e locais promovendo atribuições às autoridades mais próxima dos cidadãos, reforçando desta forma, a posição dos municípios por meio de reformas legislativas a fim de promover a legitimidade política municipal, com o objetivo de assumir responsabilidades de interesse público sobre as atividades essenciais aos direitos vitais da cidade. (BANDRÉS, 2012)

No Brasil, a autonomia dos munícipios está no resguardo do artigo 30 da Constituição Federal, o qual enumera um rol de competências atribuídas aos municípios. A leitura do artigo 23 estipula a atuação conjunta dos três entes federados, contudo, é necessário a (re)avaliação da atividade municipal, pois segundo Hermany (2007), o referido artigo apresenta matérias em que é necessário uma descentralização para que os anseios da sociedade sejam atingidos, a partir de uma proposta compartilhada dando aos atores sociais o sentimento de pertença, e não 'meros destinatários das políticas públicas', onde o indivíduo se materializa como um ser abstrato, mas sim como cidadão que cumpre com as suas obrigações de direito.

Já lecionava Lorenzo Marín Retortillo que a estrutura e a natureza dos direitos humanos se traduzem na atividade dos serviços públicos, pois a realização de certos direitos, como à educação e a saúde requer a implementação de eficiente organização administrativa, para tanto, vai depender que o cidadão tenha o direito de participar da vida política, à informação e à cultura.

Jara (1998) disserta que o desenvolvimento sustentável do município depende da descentralização de poderes sendo este o único caminho para fortalecer os mecanismos de gestão local, em detrimento dos aparelhos e práticas centralizadoras, pois essa abordagem estabelece um espaço de possibilidades operativas para atingir sustentabilidade nos planos de desenvolvimento, o que significa promover novas regras de convivência entre o governo local e comunidades, permitindo perceber com maior realismo os problemas que afetam a população local.

A descentralização sustentável, desta forma, se apresenta com uma forma de transformação do espaço local, com a participação da população para a construção de ambiente social com a participação do governo local e a comunidade. Para o autor esta visão de descentralização tem por objetivo transformar o 
município no veículo da construção da cidadania, sendo que é no espaço local que ocorre a proximidade entre governantes e cidadãos, desta forma, semeando novos valores de responsabilidade social, promovendo a solidariedade entre os atores sociais para a solução de problemas específicos. Esta aproximação funcional entre a administração pública local e a sociedade é fundamental para a realização dos direitos humanos, pois a tese de Bandrés (2012) reza que a cidade está em constante transformação de caráter público, econômico e social, devido a globalização

[...] los intensos flujos migratorios hacía los núcleos urbanos, la terciarización de la economía y los avances tecnológicos, particularmente em los ámbitos de la comunicación, que modifican el ámbito de lo público, de la política, que promueve la significación de la Administración local como "Administración de Derechos», que asume directamente responsabilidades en los ámbitos de reconocimiento, promoción y defensa de los derechos fundamentales y las libertades públicas de los ciudadanos, o como Administradores de valores, que favorece intereses vinculados a la dignidad, la paz, la solidaridad, la convivencia y la libertad.

É neste cenário que se deve promover a política pública, ou seja, é no espaço local que elas se tornam mais eficazes quando há uma comunicação maior da sociedade com o Estado permitindo, segundo Hermany (2007) uma "consolidação de uma cidadania governante", que é o propósito do princípio da subsidiariedade. Para tanto é necessário que as comunidades locais se empenhem mais em 'reivindicar a municipalização das principais políticas públicas'.

No entanto, ainda disserta o autor, que não basta uma motivação maior por parte da sociedade se não houver, também, uma mudança nas estratégias de gestão do município, com fundamentos na subsidiariedade, com o objetivo de instituir uma 'nova interpretação da repartição de competências agregada a um processo intramunicipal de democratização das decisões públicas'.

Desta forma o princípio da subsidiariedade deve ser interpretado como 'inerente à preservação das individualidades, dentro dos vários agrupamentos sociais'. É em defesa dos direitos humanos que os filósofos antigos idealizavam o princípio da subsidiariedade e que a igreja católica toma frente através das Encíclicas Papais. A subsidiariedade se traduziu num apelo dos papas aos representantes dos países desenvolvidos, em desenvolvimento e subdesenvolvidos, independente da forma de governo. Assim a subsidiariedade se materializou no apelo de Pio XI na Encíclica Quadragesimo Anno.

Como é injusto subtrair aos indivíduos o que eles podem e efetuar com a própria iniciativa e indústria, para confiá-lo à coletividade, do mesmo modo passar para uma sociedade maior e mais elevada o que sociedades menores e inferiores podiam conseguir, é uma injustiça, um grave dano e perturbação da boa ordem social. O fim natural da sociedade e da sua ação é coadjuvar os seus membros, não destruí-los nem absorvê-los.

O princípio da subsidiariedade se traduz assim na forma de amparo aos direitos humanos, pois visa proteger o cidadão, a sociedade e a comunidade dos abusos das instâncias superiores. O que nos remete ao pensamento do Estaregista onde a sociedade civil não se resume numa associação unitária, nela os indivíduos se reúnem para conseguir o que cada um na sua individualidade não conseguiria obter.

Aristóteles (1985) defendia a sua cidade como sendo uma espécie de comunidade que se forma com vistas a um bem comum. A cidade por sua vez é composta por famílias, que de uma forma ou de outra contribuem para a formação da cidade, pois cada família possui uma especialidade para suprir suas 
necessidades. Desta forma, cada cidadão atua como protagonista na construção e na preservação dos direitos humanos.

A terminologia 'direitos humanos' é empregada para denominar os direitos positivados nos documentos internacionais. Possuem um caráter descritivo (direitos e liberdades reconhecidos nas declarações e convenções internacionais) como também um caráter prescritivo (alcançam as exigências mais vinculadas ao sistema de necessidades humanas e que, devendo ser objeto de positivação, ainda assim, não foram consubstanciadas).

As declarações de direitos têm força na medida em que os textos constitucionais erigem seus ditames como princípios informadores e de validade de toda ordem jurídica nacional, e valem na medida em que esta mesma ordem jurídica está preparada para torná-las efetivas. Assim sendo, algumas ações significativas, são identificadas especialmente no fim da Segunda Guerra Mundial, acerca do processo de internacionalização dos direitos humanos. O sistema internacional de proteção dos direitos humanos ganha força e destaque a partir de 1945, com a proclamação da Carta da ONU.

Em 1948, a ONU descreveu o significado de direitos humanos na Declaração Universal de Direitos Humanos. Hoje não há povo que negue uma Carta de Direitos e o respectivo mecanismo de efetivação, o que, todavia, ainda não significa uma garantia de justiça concreta. Verifica-se que este caminho foi longo e que foram criadas paulatinamente as instituições jurídicas de defesa da dignidade humana.

Os Direitos Humanos obtiveram um enorme crescimento nos últimos anos, mas segundo Noberto Bobbio, "o problema grave de nosso tempo, com relação aos direitos do homem, não era mais o de fundamentá-los, e sim de protegê-los". Na verdade, devem ser colocados à disposição dos indivíduos ferramentas para que os direitos humanos sejam protegidos na esfera internacional e no âmbito dos Estados nacionais. De tal modo que, os Direitos humanos adquiriram status oficial no discurso internacional, tornaram-se "uma parte importante da literatura do desenvolvimento". Três preocupações distintas com relação ao edifício intelectual dos direitos humanos, na visão de Amarthya Senn:

Argumentação crítica da legitimidade: "Receio de que direitos humanos confundam consequências de sistemas legais, que conferem às pessoas direitos bem definidos, com princípios pré-legais que não podem realmente dar a uma pessoa um direitos juridicamente exigível." Diz respeito a legitimidade das reivindicações de direitos humanos. Os direitos humanos são adquiridos por meio da legislação. Não existem direitos pré-legislação (Karl Marx, direito não pode preceder a instituição do Estado). Reconhecimento da importância ética de que certos direitos constituem pretensões éticas próprias de todos os seres humanos, mas que não precisam, necessariamente, ser legislados;

Argumentação crítica da coerência: relaciona-se a forma assumida pela ética e pela política dos direitos humanos. Direitos são pretensões que requerem deveres correlatos, sob pena de esvaziarem-se. $O$ direito de um corresponde ao dever de outrem. Os direitos humanos aqui não são vistos como comuns a todos, como benefícios que todos deveriam ter. "A asserção ética de um direito ai além do valor da liberdade correspondente apenas na medida em que se exige de outras pessoas que elas tentem ajudar";

Argumentação crítica cultural: direitos humanos pertencem ao domínio da ética social. Para justificar o seu nome exigem universalidade, mas não existe identidade de valores universais. Ex. oriente e ocidente. Na Ásia vive cerca de $60 \%$ da população mundial. "não há valores quintessências que se apliquem a essa população imensa e heterogênea, nenhum valor que a distinga como um grupo separado do restante do mundo"; 
No se trata sólo de incrementar uma conciencia y uma cultura jurídica de protección, sino, además, potenciar uma cultura de derechos humanos en general, integral, porque, em realidade, somos todos los seres humanos ahí donde nos movemos quienes, utilizando o no utilizando la vía jurídica, participamos em los processos de construcción o destrucción de derechos humanos, seamos o no seamos juristas.

Para Amarthya Senn, o caráter e protagonismo dos direitos humanos não devem estar alicercado de forma única e exclusiva as dimensões normativas, ainda que imprescindível o papel do direito e dos sistemas de proteção aos direitos humanos na órbita internacional e nacional. Neste cenário ocorre a valoração do ser humano como pessoa e não como mero telespectador da vida política, pois como tal ele deve ser visto e para tal ele deve, também participar. Da mesma forma o Estado deve buscar o desenvolvimento da cidadania, permitindo que o homem, independente do gênero, cor e nacionalidade participem da vida política para a construção e preservação dos direitos humanos a ele inerente.

\section{Desastre Ambiental}

Nas últimas décadas o Brasil assim como o resto do mundo vem sofrendo com os desastres naturais de origem hidrometerológica, como enchentes e inundações, secas e ciclones tropicais, devido à globalização das massas e a consequente ocupação de áreas de risco (ZAMPARONI et al., 212).

A repercussão sobre problemas causados pelo aquecimento global tem mobilizado as organizações internacionais, assim como a Organização das Nações Unidas (ONU) e suas entidades, como o Intergovernmental Panel on Climate Change - IPCC - a estudos e debates mais aprofundado sobre o tema, resultando em diagnósticos e prognósticos para as diferentes áreas do globo (CIDADE, 2012).

Segundo o relatório do IPCC os impactos das mudanças climáticas variam de lugar para alugar, no entanto na América latina, devido ao aumento de temperatura decorrente da redução de água no solo, a floresta amazônica oriental se reduziria a uma vegetação de cerrado, bem como a sanalização e desertificação das terras agrícolas, elevação do nível do mar aumentando o risco de inundações em áreas baixas, etc. (CIDADE, 2012).

Conforme o Intergovernmental Panel on Climate Change o monitoramento de desastre natural de origem hidrometerológica é de suma importância, pois é a partir deste monitoramento que se elabora o planejamento de ações preventivas e a definição de políticas públicas. Qualquer medida que vise limitar impactos climáticos na sociedade deve levar em consideração que o 'ambiente atmosférico é altamente dinâmico', e está em constante transformação). O relatório sobre mudanças climáticas de 2007 confere algumas sugestões para a mitigação dos desastres ambientais, entre os quais estão a "inclusão de medidas adaptativas no planejamento de uso do solo e nos projetos de infraestrutura," e o uso de medidas visando reduzir a vulnerabilidade à redução de riscos de desastres.

Diante deste quadro de desastre e catástrofes ambientais encontram-se as populações de risco, as quais variam de lugar para lugar, dependendo do território nacional. As mais favoráveis a sentirem os rancores da natureza são as populações faveladas, devido ao local de seu assentamento, geralmente a beira de rios e sobre montanhas, transformando a mata nativa em verdeia selva de pedra. Segundo Oliveira (2012), 
o problema destes assentamentos está no fator solo que são terras ecologicamente frágeis, como montanhas, terras semiáridas e áreas tropicais úmidas.

Tosa essa recriação e transformação do espaço natural, convertidos ao consumo de massa ocasionou problemas que colocaram a sociedade moderna em constante risco que não são possíveis de prever e nem de controlar, gerando as chamadas catástrofes ambientais, expondo a vulnerabilidade das sociedades e originam uma sociedade oriunda de riscos ambientais.

\section{METODOLOGIA}

O método adotado na consecução do presente artigo é de natureza bibliográfica, será utilizado quanto ao método de abordagem a ser adotado no seu desenvolvimento o dedutivo, tendo pressuposto argumentos gerais (premissa maior) para argumentos particulares (premissa menor); enquanto o procedimento será analítico.

\section{RESULTADOS E DISCUSSÃO}

Por conseguinte, os conceitos de desastre a partir da teoria de Quarantelli e Nasreen, que definem o desastre tanto como uma 'situação coletiva de stress', quanto 'à ruptura do funcionamento de um grupo na sua base territorial, a um período de crise social'. Sob esta perspectiva, o 'desastre é visto como um fenômeno próprio à dinâmica social', desta forma, é no 'interior da mesma que se identifica os limites da ação técnica', quer seja para evitar o problema como para a sua inercia. A catástrofe por sua vez, depende de fatores sociopolíticos como a limitação material de recursos 'do grupo afetado para o seu autoatendimento; expectativa de providências por parte do ente público; e, o imobilismo e conflito entre autoridades de escalas diferentes', fatores estes observado em vários casos ocorridos no Brasil.

Diante destes problemas, surgem os desabrigados que, segundo a Defesa Civil, 'é a pessoa cuja habitação foi afetada por dano ou ameaça de dano e que necessita de abrigo provido pelo sistema', enquanto desalojado é 'aquele que sai de casa', não necessariamente perdeu a casa, e encontra-se em casa de amigos e parentes.

Estes desabrigados são confinados em lugar temporário, que pode ser uma escola ou um ginásio. Contudo os ânimos nem sempre são os melhores, o que leva a constantes conflitos com os gestores, e a administração pública passa a ver os abrigos como um lugar de difícil administração, devido à "indisposição dos gestores para lidar com seu funcionamento e o desejo de desativar o estabelecimento público para essa função". Os desabrigados vivem em uma situação de holocausto, pois são alojadas em escolas, igrejas e complexos esportivos. Estes espaços passam a configurar o total desrespeito com a dignidade humana e social, pois servem de meio para "deteriorar definitivamente a espacialização das relações comunitárias e privadas dissolvendo-se umas nas outras" onde vivem diariamente sem a privacidade que o lar antes Ihes proporcionava. As regras de convivência são reguladas por um gestor externo, terminando com a relação familiar entre mãe e filho, marido e mulher. (VALENCIO, 2006)

A demora da reterritorilização dos desabrigados, nessa perspectiva, ocorre devido à burocratização, o que motiva a descrença do Estado como instituição que lhes deve satisfação. A título de exemplo, Valencio (2006) cita o caso dos desabrigados no município de Jaboatão dos Guararapes em Pernambuco, onde os moradores esperam por mais de dois anos "uma solução de moradia que não aparecia devido à falta de 
integração entre os três níveis de governo responsáveis pelo processo". Valencio (2006) afirma que a União iria liberar os recursos somente se o estado apresentasse a área para implantação do projeto habitacional de recolocação de famílias. Os terrenos apresentados, sucessivamente, não atendiam os critérios, por conseguinte as verbas disponibilizadas permaneceram sem uso, e, por conseguinte, o município que faria a gestão do processo de reconstrução, permaneceu inoperante.

Os desastres ambientais são espaços propícios para a reflexão da subsidiariedade, pois se comprova no quadro do pós-impacto as insuficiências e faltas de recursos em desastres inesperados, cujo caso se apresenta por uma única falha, ou seja, da falha político administrativa, que se manifesta, segundo MillonDelsol (1993) pela concorrência excessiva de poder traduzindo-se em uma luta desleal em imposição de uma ordem maior com vistas a restaurar a ordem do caos.

Neste quadro ocorrem dois fatores de inércia, um provocado pela própria gestão pública, ou seja, pela falta de articulação entre os três poderes, o que leva a burocratização estatal, e a inercia da sociedade afetada, na expectativa de um desenrolamento do entrave entre as três esferas de poder, ou seja, as famílias afetadas não procuram meios de se auto-organizarem para a solução de seus problemas, tão pouco, é possibilitado à articulação entre os entes sociais e a administração pública na busca da solução mais favorável.

O Estado democrático não se faz presente, pois a população afetada pelos desastres esperam um tomada de decisão dos agentes governamentais, ao invés de exercerem os seus direitos políticos. A centralização das decisões continua enraizada no sistema político centralizado e intervencionista, não abrindo espaços para que a comunidade afetada possa contribuir para que uma melhor decisão possa ser tomado no que diz respeito a assistência ao pós-impacto e nos planos de contingência.

A política para alojar os desabrigados no Brasil anda contramão ao que se propõe a subsidiariedade, invocada pelo Papa Pio XI, na proteção dos cidadãos contra o abuso da administração pública central, sendo está, vestido de pessoa, que diante de atribuição de poder e especificidade tem por obrigação dar assistência às esferas intermediarias para desempenharem com eficiência as suas atividades. Nestas circunstancias a políticas públicas formam verdadeiros centros de convivência vertiginosa, indo contra os preceitos constitucionais da dignidade humana, e do significado de suplência garantido pelo princípio da subsidiariedade.

O que vem ser política do pós-impacto? Pode-se dizer que seja os resultados dos desastres ou catástrofes derivado de alterações climáticas que vão se manifestar de acordo com o seu grau no plano social de políticas públicas. Toma-se a exemplo um furacão que atravessa o território nacional, levando em conta que durante o seu trajeto a sua potência continua a mesma. Ele atravessa o território nacional e por onde ele passa deixa um rastro de destroços e de vítimas. Contudo o número de vítimas e de destroços vai variar de lugar para lugar, devido a sua construção sócio política, ou seja, antes do furacão passar tem-se um cenário de aplicação de política pública que vai influenciar no pós-impacto. (VALENCIO, 2006)

Desta forma, os impactos ambientais se refletem na estrutura "dinâmica da organização social, tirando-se, assim, o foco do fator de ameaça e valorizando as relações sócias e políticas que se refletem territorialmente" (SIENA et al., 2009). O grau de risco ambiental é calculado a 'partir da frequência e das 
consequências do evento, englobando em torno da repercussão para a sociedade'. Desta feita, a comunicação se torna um fator importante, pois é a partir da comunicação que ocorrerá uma distorção do fato real, para mais ou para menos, a fim de evitar, a generalização, da sensação de medo e perigo, na sociedade (TEODORO et al., 2010).

Tendo em vista que o modo de como ocorreu à comunicação ela influenciará no entendimento da função da coordenação da ação, tendo em vista que, a "relação entre facticidade e validade se modificam" quando a linguagem passa a ser considerada como um médium universal de incorporação da razão" (HABERMAS, 1997). Os procedimentos formais que institucionalizam a opinião e a vontade, ou ainda, apenas informalmente, nas redes da esfera pública política, mantendo um nexo interno com os contextos do mundo da vida racionalizado, filtradas deliberativamente.

No ambiente a comunicação é a síntese da informação, da mensagem e da compreensão, contudo esta comunicação somente é possível em um ambiente onde se reproduz a comunicação (LUHMANN, 2010). A teorização luhmanniana se articula em torno de 'lugares' primordiais, tais como a complexidade, o sistema e seu ambiente, a dupla contingência, o sentido, o fazer experimentar e o agir, a comunicação, o tempo, a auto referência tendo por elemento um fluxo cognitivo que a torna extremamente sensível a incidentes de estipulações e de irritações provenientes de todos os tipos de pesquisas em ciências humanas.

A partir de então se pode dizer que há uma interação entre indivíduos que se identificam pela forma e pelo conteúdo, estabelecendo uma linguagem coerente com o discurso. Para que a comunicação atinja o seu objetivo, para que tenha eficiência e eficácia se faz necessário a existência de códigos binários entre emissor e receptor de entendimento e apreensão de cada operação, bem como de expressão e emoção dos atores intervenientes no processo comunicativo, e não somente de sinais gráficos (TEODORO et al., 2010).

Estes canais de comunicação se conectam por meio das redes de interação de atores sociais, de modo a ampliar, sem destruir, as estruturas espaciais de interação, favorecendo a orientação pelo entendimento de que, a comunicação não ocorra semente na comunidade tendo que envolver todos os demais atores da sociedade civil e política (HABERMAS, 1997).

Decorre o que Habermas chama de solidariedade concentrada no papel do cidadão que se constitui no próprio agir comunicativo, gerando práticas de autodeterminação organizadas, mediadas através de instituições e processos jurídicos, e mesmo através de movimentos autogeridos pelos atores sociais (organizações não-estatais) (LEAL, 2011). A comunicação apresenta uma dupla contingencia, ou seja, a forma como foi transmitida influenciará nos resultado de tal forma que as medidas tomadas para a decisão de uma determinação ação poderia ser outra mais eficaz ao problema (LUHMANN, 2011).

A comunicação é relevante no sistema de rede entre a sociedade e os entes federais, pois é por meio desta relação de canais abertos que a administração pública consegue captar e tematizar os problemas enfrentados pela sociedade de desastre ambiental, e principalmente aproximar a sociedade aos entes políticos na formulação e implementação de ações que podem resultar em políticas sociais, no caso em questão de política pública de Defesa Civil. A subsidiariedade é o remédio que Delpree afirma para a solução 
dos pequenos e grandes problemas da sociedade, que por sua vez contempla a defesa dos direitos humanos, que Pio XI rogou aos governos em defesa dos seus cidadãos.

\section{CONCLUSÕES}

O paradigma lançado segundo as bases da teoria das Encíclicas Papais é demarcar a numa perspectiva liberal a valorização das liberdades individuais, do bem comum, a propriedade privada, da justiça social, a dignidade da pessoa humana, da cidadania, mas também ampliando as condições para a descentralização de poderes, isto é, que o Estado, aqui entendido o Município, seja composto de vários níveis de decisão e de autonomia para uma gestão pública compartida, no sentido prestigiar a atuação dos níveis governamentais mais próximos dos cidadãos para a tomada de decisão/atuação, numa relação comunicativa de mutuo respeito em níveis de maior proximidade com o cidadão no interior do espaço local, fortalecendo as relações políticas, humanas, econômicas, sociais e das instituições democráticas e da comunidade.

A grande alavanca no processo de internacionalização dos direitos humanos foi a Carta das Nações de 1945. Existe uma grande preocupação na tutela dos direitos humanos, evidencia-se que leões de toda ordem são processadas e aviltam a dignidade humana. Muitas lesões que são produzidas em detrimento dos direitos humanos, decorrem do momento que vive a humanidade impulsionada pela globalização exigindo a eliminação das fronteiras geográficas nacionais e difundindo contínua modernização, expansão econômica, política, militar e territorial, fundindo e/ou destruindo identidades nacionais pela a imposição de governos e modos de produção, enquanto mundializa a cultura.

A globalização trata efetivamente da transformação do espaço e do tempo, por isso não pode ser entendida apenas como um fenômeno econômico, mas uma mistura complexa de processos, que frequentemente atua de maneira contraditória, produzindo conflitos, disjunções e novas formas de estratificação, deixando o Estado deixa de exercer o papel de proporcionar o bem- estar dos seus cidadãos, ocasionando grandes desigualdades sociais e problemas, tais como, o meio ambiente e questão inerente aos desastres ambientais e seus impactos na estrutura dinâmica da organização social, excluindo-se o fator de ameaça e valorizando as relações sociais e políticas que se refletem territorialmente, sendo importante o computo do risco ambiental a partir da frequência e das sequelas do evento, em torno da repercussão no tecido social, especialmente, as pessoas em situação de vulnerabilidade.

Os direitos humanos, apesar de serem difundidos em quase todos os cantos do planeta e despertarem verdadeiro interesse da sociedade internacional, esbarram no entrave da globalização econômica, transformando grande parcela da população em excluídos globalizados. Nesse mister, urge há necessidade de estabelecimento de uma nova relação entre o espaço público local e a comunidade, a partir dos referencias teóricos e pragmáticos do princípio da subsidiariedade, como suporte da autonomia política e descentralização administrativa, contrapondo a intervenção estatal centralizada.

O princípio da subsidiariedade encontra aplicação, uma vez que, em sua acepção de complementariedade, propõe a participação social de cada cidadão e sua respectiva atuação na preservação dos direitos humanos e ambientais no espaço local objetivando a efetivação das demandas sociais referente 
à prevenção dos desastres ambientais e a comunicação entre os desabrigados no âmbito municipal, em todas as esferas da ação política gestacional e do meio ambiente, assim como, das demandas comunitárias aproximando a sociedade civil aos entes políticos na formulação/implementação de ações políticas concretas por parte das vítimas dos desastres/catástrofes ocorridas no meio ambiente, manifestando-se de acordo com o seu grau no plano social de políticas públicas.

\section{REFERÊNCIAS}

ARISTÓTELES. A Política. Brasília: Universidade de Brasília, 1985.

BANDRÉS, S. C. J. M.. 16 Ensaios sobre Democracia, justiça y derechos humanos. Zaragoza: 2012.

BARACHO, J. A.. O princípio de subsidiariedade: conceito e evolução. Rio de Janeiro: Forense, 1996.

BENOIST, A.. The First Federalist: Johannes Althusius. Telos, v.200, n.118, p.25-58, 2000.

CIDADE, L. C. F.. Política, sociedade e ambiente. In: RIBEIRO, A. C. T.; LIMONARD, E.; GUSMÃO, P. P.. Desafios ao planejamento: produção da metrópole e questões ambientais. Rio de Janeiro: ANPUR, 2012.

DELPEREE, F.. Le principe de subsidiarité. In: Colloque AEFLIB. Anais. Paris: 2013.

ETZIONE, A.. La terceira via havia uma buena sociedade: propuestas desde el comunitarismo. Madri: Minima Trotta, 200.

GUERRA, S.. Direitos Humanos e Cidadania. São Paulo: Atlas, 2012.

HABERMAS, J.. Direito e Democracia: entre facticidade e validade. Tradução de Flávio Beno Siebeneichle. Rio de Janeiro: Tempo Brasileiro: 1997.

HABERMAS, J.. Direito e Democracia: entre facticidade e validade. Rio de Janeiro: Tempo Brasileiro: 1997.

HERMANY, R.. (Re) discutindo o espaço local: uma abordagem a partir do direito social de Gurvitch. Santa Cruz do Sul: UNISC, 2007.

JARA, C. J.. A sustentabilidade do desenvolvimento local. Brasília: IICA, 1998.

LEAL, R. G.. A democracia deliberativa como nova matriz de gestão pública: alguns estudos de casos. Santa Cruz do Sul: EDUNISC, 2011.
LUHMANN, N.. Introdução à teoria dos sistemas. 3 ed. Petrópolis: Vozes, 2011.

MILLON-DELSOL, C.. Le principe de subsidiarité. Paris: Presses Universitaires de France, 1993.

MILLON-DELSOL, C.. L'Etat subsidiaire: ingérence et noningérence de l'Etat: le principe de subsidiarité aux fondements de l'histoire européenne. Paris: Presses Universitaires de France, 1992.

OLIVEIRA, M. J. G. S.. Políticas públicas e o meio ambiente: a questão dos desastres ambientais e seus efeitos na sociedade de risco do brasil. CONGRESO DE MEDIO AMBIENTE, 7. Anais. La Plata, 2012.

RUBIO, D. S.. Repensar os Direitos Humanos: de la anestesia a la sinestesia. 1 ed. Madri: Editorial MAD, 2007.

SEN, A.. Desenvolvimento como liberdade. São Paulo: Companhia das Letras, 2000.

SIENA, M.; VALENCIO, N.. Gênero e desastres: uma perspectiva brasileira sobre o tema. In: VALENCIO, N.; SIENA, M.; MARCHEZINE, M. C. J.. Sociologia dos desastres: construção, interface e perspectivas no Brasil. São Carlos: RiMa Editora, 2009. p.69-80.

TEODORO, P. H. M.; AMORIN, M. C. C. T. Riscos e impactos como produtos das práticas socioespaciais: um estudo prognóstico da cidade de Maringá/PR, Brasil. In: Revista Territorium, Coimbra, n.17, p.168-180 2010.

VALENCIO, N.. Da 'área de risco' ao abrigo temporário: uma análise dos conflitos subjacentes a uma territorialidade precária. In: VALENCIO, N.; SIENA, M.; MARCHEZINE, M. C. J.. Sociologia dos desastres: construção, interface e perspectivas no Brasil. São Carlos: RiMa Editora, 2009. p.1934.

ZAMPARONI, A. G. P.; NUNES, L. H.. Desastres naturais de origem atmosférica e seus impactos em Moçambique. In: LIMA-GUIMALHÃE, S. T.; CAPRI JUNIOR, S.; BARRIOS, M. B. R.; TAVARES, A.. Gestão de riscos e desastres ambientais. Rio Claro: IGCE, 2012. 